\title{
How higher education students in Egypt perceived online learning engagement and satisfaction during the COVID-19 pandemic
}

\author{
Ghada El-Sayad $^{1,2}$ (D) Nor Hasliza Md Saad ${ }^{2}$ Ramayah Thurasamy $^{2,3,4,5}$ (D)
}

Received: 18 September 2020 / Revised: 16 March 2021 / Accepted: 21 May 2021 /

Published online: 23 June 2021

(C) Beijing Normal University 2021

\begin{abstract}
This study aims to examine the influence of academic self-efficacy, perceived usefulness of online learning systems, and teaching presence on student engagement (behavioural, emotional, and cognitive engagement) and student satisfaction with online learning. Data were collected from undergraduate students who experienced a fully online learning process during the COVID-19 pandemic. Based on social cognitive theory, the relationships among the personal and environmental influences on student behaviour and outcomes were examined using structural equation modelling. The results indicated that academic self-efficacy had significant direct relationships with behavioural engagement and emotional engagement, while perceived usefulness significantly influenced emotional engagement and cognitive engagement. Furthermore, teaching presence significantly influenced all engagement dimensions. Student satisfaction was significantly and directly influenced by behavioural engagement and emotional engagement, but not by cognitive
\end{abstract}

Ghada El-Sayad

ghadaelsayad@aast.edu; ghadaelsayadaast@gmail.com

Nor Hasliza Md Saad

norhasliza@usm.my

Ramayah Thurasamy

ramayah@usm.my; ramayah@utar.edu.my

1 College of Management and Technology, Arab Academy for Science, Technology and Maritime Transport (AAST), Square 1175, Sheraton Bldg, Heliopolis, Cairo, Egypt

2 School of Management, Universiti Sains Malaysia, 11800 Minden, Penang, Malaysia

3 Department of Management, Sunway University Business School (SUBS), Petaling Jaya, Malaysia

4 Faculty of Economics and Business, Universiti Malaysia Sarawak, Kota Samarahan, Sarawak, Malaysia

5 Faculty of Accounting and Management, Universiti Tunku Abdul Rahman (UTAR), Kampar, Perak, Malaysia 
engagement. Finally, the mediation role of each engagement dimension is proven in this study. This study was conducted in Egypt; thus, it contributes to add an empirical evidence regarding online student engagement and satisfaction in the context of a developing country.

Keywords Online learning $\cdot$ Student engagement $\cdot$ Student satisfaction $\cdot$ Social cognitive theory

\section{Introduction}

The COVID-19 pandemic has affected communities, businesses and economies around the world; it has also affected higher education institutions (UNESCO, 2020). The pandemic has also imposed a certain degree of change upon higher education institutions, as campuses have been shut down by authorities across the globe in an attempt to curb the spread of the virus. Consequently, higher education institutions across the world found themselves in a race to immediately introduce online learning options for staff and students (UNESCO, 2020). This sudden change has proven challenging for both students and educators, who have had to adjust to a very different approach, moving from an expectation of face-to-face classroom interactions to a requirement to rapidly adapt to online classes from remote locations, combined with a lack of social contact. This situation has forced higher education institutions to change their focus towards effectively delivering online education and assessing outcomes to their students' satisfaction.

Many studies that have investigated the effects of COVID-19 on higher education were carried out in developed countries, specifically, in the USA and Europe (Johnson et al., 2020; Wotto, 2020). However, due to how suddenly COVID-19 emerged, most higher education institutions in developing countries faced the challenges of lack of preparation and understanding of online learning outcomes. Developing countries represent different levels of economic development, technological infrastructure, and different social and cultural environments. Arab countries, such as Egypt, Saudi Arabia, Jordan, and United Arab Emirates, have a growing interest in online learning; however, it remains in its initial stages, especially in comparison with Western countries (Adel, 2017). The pandemic of COVID-19 has also come across several obstacles concerning online learning in many Arab countries (Lassoued et al., 2020). For example, several students suffer from not receiving a proper training before using online learning systems and, in some cases, they have to use inflexible online learning systems (Diab \& Elgahsh, 2020). Besides, they also suffer from lack ICT infrastructure including low bandwidth connections and Internet inaccessibility, specifically in many rural and remote areas (Diab \& Elgahsh, 2020; Lassoued et al., 2020). Moreover, one of the ramifications of the pandemic which obliged almost all of the students to stay and learn in their homes, for their safety, is that various students from the same family are compelled to attend online classes from the same place and at the same time. This causes online learning at homes not to be the most suitable environment for online learning. These obstacles 
significantly reduce the quality of online learning and affect students' motivation and participation during the online learning.

Egypt, as a developing country, has been developing its information and communication technology (ICT) infrastructure since 1985, and it continues to promote it in education-especially higher education-in order to foster the motivation of instructors and students to learn (El-Khouly, 2018; Kamel \& Hussein, 2002). Internet users in Egypt have significantly increased over the past six years from 2013 to 2019 to reach approximately 51 million users. $73.81 \%$ of them are tertiary students, and $44.3 \%$ of their Internet activities are for educational purposes (MCIT, 2015). As a lot of students in Egypt rely mainly on online learning since the outbreak of the pandemic, Internet access has reached 57.3\% (MCIT, 2020a, 2020c). Moreover, at the end of July-September 2020, the usage of Mobile devices has reached $94.09 \%$ and increased to $95.37 \%$ by November 2020 (MCIT, 2020b, 2020c). This dependency on Internet networks and digital systems urges the Egyptian government to make crucial decisions regarding the improvement of the ICT infrastructure.

The Egyptian higher education system comprises 24 governmental universities, 26 non-governmental universities, and 158 special higher education institutes (MOHESR, 2017). This extensive higher education system serves a growing number of tertiary students every year (MOHESR, 2016). In order to fulfil the needs of students and improve and develop the quality of higher education, the ministry of higher education has focused on a digital transformation strategy that has seen them direct their funding towards online learning systems projects since 2004 (MCIT, 2009; SCU, 2018). Since the recent coronavirus outbreak in mid-March, several undergraduate students in Egypt have continued their academic studies through a fully online learning process (Mahmoud, 2020; Mai, 2020). On one hand, several higher education institutions in Egypt have benefited from Internet facilities in delivering the learning content either through the formal educational platforms such as, for example, Moodle platform, universities' websites, or through free communication platforms such as Google classroom and Zoom meetings (Sobaih et al., 2020). On the other hand, various faculty members use many social networking sites such as WhatsApp, Facebook, and YouTube for an easily communication with their students (Sobaih et al., 2020). Consequently, considerable efforts are devoted to decrease the technology literacy for both students and instructors. In this regard, these higher education institutions have become more aware of the importance of online learning not only to overcome this unprecedented situation but also to respond to the other pressing educational challenges for the future development of the Egyptian higher education in general.

A digitised learning process, in which students are far from their instructors and peers and interact more with an online learning system, may have an effect on student engagement and, in turn, outcomes. Student engagement in learning environments that are mediated by technology is a key challenge that can hinder the effectiveness of online learning (Henrie et al., 2015; Oncu \& Cakir, 2011). In higher education, the engagement of online students is associated with important outcomes such as student satisfaction, perception of learning, and learning persistence (Bolliger \& Halupa, 2018; Gray \& DiLoreto, 2016; Jung \& Lee, 2018). Many studies have investigated student perception and attitudes towards online learning in the context of 
Egyptian higher education (El Gamal \& Abd El Aziz, 2012; El-Seoud et al., 2014). However, there has been limited research into the behaviour of online undergraduate students, and therefore, little is understood about how their behaviour affects the attainment of outcomes. This study seeks to apply social cognitive theory (SCT) to fill in this gap by investigating the personal and environmental influences that affect the engagement and satisfaction of online students. SCT illustrates how personal and environmental influences proactively shape individual behaviour. Accordingly, the current study attempts to explore the structural relationships between academic selfefficacy (as a personal influence), perceived usefulness and teaching presence (as environmental influences), student's behavioural, emotional, and cognitive engagement (behaviour), and student satisfaction (as an outcome) in online learning. Prior studies have confirmed the significant effects of academic self-efficacy, perceived usefulness, and teaching presence on online student engagement (Gray \& DiLoreto, 2016; Jung \& Lee, 2018; Martin et al., 2018; Zhai et al., 2018), however the effects on each engagement dimension were unclear. Likewise, many empirical evidences have revealed that online student engagement significantly influences their satisfaction (Bolliger \& Halupa, 2018; Fisher et al., 2018; Gray \& DiLoreto, 2016); however, the unique effect of each engagement dimension on student satisfaction with online learning was not investigated. Therefore, the current study addresses these gaps through examining the research model proposed in this study.

In this ever-changing environment, understanding the adaptive behaviours of students is critical for student outcomes. With the goal of providing useful insight for other higher education institutions to effectively identify student outcomes for online learning, this study examines how undergraduate students at one educational institution in Egypt identified the satisfaction of its online students during the COVID-19 pandemic.

\section{Theoretical background}

\section{Social cognitive theory}

SCT is a psychological perspective on student functioning that illustrates the critical role played by personal influences and situational demands (environmental influences) in the execution of student behaviour (online engagement) (Bandura, 1986). Consistent with student engagement, social cognitive theorists have articulated that student behaviour can be shaped based on the situation or environment-in other words, the context—in which they learn (Bandura, 1997; Reschly et al., 2008). Furthermore, they assert that personal influences, such as students' beliefs regarding anticipated outcomes and their own capabilities are motivational factors that contribute to the shaping of their behaviour (A.L. Reschly \& Christenson, 2012).

SCT is a fairly broad theory of human behaviour which can be applied to the context of the Internet as a type of media (LaRose \& Eastin, 2004). Educational literature has demonstrated the impact of the learning environment on student behaviour (Wu et al., 2010). More specifically, the physical and social environments were identified as terms of the face-to-face learning context (Wu et al., 2010). In contrast, 
in the context of online learning environments, the environmental influences include technology, content, interaction, learning model, and student control (Piccoli et al., 2001). These environmental influences are categorised into the technological environment and the social environment (Wu et al., 2010). The technological environment describes the online learning system's functionality; the fact of online learning systems in themselves must be considered, with a focus on their applicability and functionality (Wang \& Lin, 2007). The social environment refers to social interactions and the learning climate in general.

\section{Student engagement and satisfaction in online learning}

\section{Student engagement}

Engagement refers to the effort that is continuously spent by students towards their learning process in order to achieve their desired learning goals (Coates, 2006). Student engagement is a multidimensional construct that involves behavioural, emotional, and cognitive dimensions (Fredricks et al., 2004). Behavioural engagement describes student participation in academic activities. Emotional engagement refers to students' positive or negative attitudes towards their instructors, colleagues, academics, and the educational institution to which they belong, while cognitive engagement reflects student investment in learning for understanding and mastering difficult concepts. Many studies of online students engagement have focused on the behavioural dimension of student engagement, including the number of lecture videos that are viewed, the number of posts that are made in discussion forums, and how many quizzes and assignments are completed, to measure student engagement (Hew, 2016; Hu \& Hui, 2012; Hui et al., 2019; Ma et al., 2015). Fredricks et al. (2004), however, demonstrated the central concern of measuring student engagement using a single dimension, which ignores its multidimensionality. Thus, this study concentrates on the behavioural, emotional, and cognitive engagement dimensions of student engagement, which are the most prevalent and interrelated (Fredricks et al., 2004).

\section{Student satisfaction}

It is important to evaluate the affective outcomes of student engagement, such as student satisfaction, which reflects student attitudes (Kuo et al., 2014). Student satisfaction demonstrates students' perception of their learning experience (Alqurashi, 2019) and is considered as an essential indicator of student outcomes (Zhang, 2003); it is also important for evaluating the effectiveness of the online learning process (Alqurashi, 2019). Furthermore, student satisfaction levels allow institutions to explore methods to improve and develop their online courses, and it is also associated with student retention and willingness to continue and complete the online course (Ali \& Ahmad, 2011; Debourgh, 1999; Kuo et al., 2014). 


\section{Factors influencing online student engagement and satisfaction}

\section{Academic self-efficacy}

Self-efficacy is the core of SCT; it is also a significant personal influence that often affects student motivation, and it is associated with behavioural change (Bandura, 1986, 1997). Self-efficacy refers to confidence in one's ability to organise and perform the actions required to attain a desired outcome (Bandura, 1977). The current study concentrates on academic self-efficacy as a personal influence, specifically, students' academic self-efficacy in online learning. Academic self-efficacy refers to students' believes of their ability to accomplish learning tasks and confidence in their own skills to successfully perform these tasks (Pintrich et al., 1993). Academic self-efficacy was indicated to have a significant influence on student engagement in different online learning contexts; specifically, it has a significant and positive effect on student engagement with learning through massive open online courses (MOOCs) (Jung \& Lee, 2018), students' cognitive engagement in blended learning (Manwaring et al., 2017), and students' psychological engagement in distance learning (Vayre \& Vonthron, 2017). Academic self-efficacy also acts as a significant predictor of student satisfaction with online learning (Alqurashi, 2019; Jan, 2015). In fact, studies demonstrated that students who have higher academic self-efficacy with regard to their ability to perform online tasks are more engaged with their learning, which accordingly contributes to their satisfaction with and willingness to complete an online course (Jan, 2015; Jung \& Lee, 2018).

\section{Perceived usefulness}

Technology acts as a facilitator of student engagement (Gunuc \& Kuzu, 2015), and it has been shown that student behaviour (e.g. students' online engagement) is significantly and positively influenced by technology use (Rashid \& Asghar, 2016). Burch et al. (2017) articulated that students' impressions of their engagement with online tasks and activities may depend on the characteristics of the online learning system, especially with respect to its usefulness, and that this relationship should be studied further. The notion of perceived usefulness arises from the technology acceptance model, which describes individuals' beliefs that their job performance can be enhanced through the use of a particular system (Davis, 1989). Therefore, in online learning environments, perceived usefulness can demonstrate students' perception that online learning can benefit them through better performance or learning. Prior studies have indicated that perceived usefulness has a significant effect on online student engagement in MOOCs (Jung \& Lee, 2018), game-based learning (Ab Rahman et al., 2019; Thongmak, 2018; Zhai et al., 2018), and blended learning (Fisher et al. 2018). Furthermore, perceived usefulness is a predictor of student satisfaction with online learning (Al-Samarraie et al., 2018; Hui et al., 2019). 


\section{Teaching presence}

Teaching presence is a multidimensional construct that describes students' perceptions that the instructor facilitates their learning through instructional design and organisation, discourse facilitation, and direct instruction (Anderson et al., 2001). Instructional design and organisation is considered as the main roles of instructors in setting learning discourse, context, and content of the online course based on its objectives. Discourse facilitation refers to when instructors provide feedback to encourage their students in order to maintain their involvement in the learning process, while direct instruction involves instructors sharing their knowledge of subject matter with students (Anderson et al., 2001). Therefore, teaching presence is a key consideration when examining instructors' roles in delivering successful online teaching and learning processes; it is also important for developing higher levels of community among online studentsteaching presence encourages students to interact collaboratively, which promotes feelings of relatedness (Shea \& Bidjerano, 2009). Studies have shown that instructor support and presence is a predictor of student engagement (Gray \& DiLoreto, 2016; Jung \& Lee, 2018; Martin et al., 2018; Vayre \& Vonthron, 2017) and satisfaction in online learning environments (Eom \& Ashill, 2016). Therefore, online course instructors play an essential role in online learning, not only in the context of delivering knowledge, but also in providing assistance and guidance to students, thereby boosting their engagement.

\section{Student engagement and satisfaction}

Prior studies have indicated the significant impact of student engagement on student satisfaction in different online learning contexts. For example, Murillo-Zamorano et al. (2019) found that in the case of blended learning, student satisfaction with flipped classrooms-when students use technology means such as pre-recorded videos, to attend lectures out of class time and work collaboratively under the supervision and support of online course instructors (Findlay-Thompson \& Mombourquette, 2014) was significantly and positively influenced by their engagement. Similarly, students' engagement in flipped classrooms heightened their performance and levels of satisfaction. Furthermore, Bolliger and Halupa (2018) revealed that in the context of online programs, student engagement had a significant positive association between student engagement and student outcomes, specifically with regard to their learning perception and satisfaction. The study of Gray and DiLoreto (2016) also confirmed this significant impact of student engagement on student learning in and satisfaction with online learning and also found that student engagement mediated the relationships between the presence of the course instructor and student satisfaction.

\section{Research model and hypotheses}

As can be shown in Fig. 1, this study examines the relationships between academic self-efficacy, perceived usefulness, and teaching presence and behavioural engagement, emotional engagement, cognitive engagement, and student satisfaction in 
the online learning environment. Accordingly, the following hypotheses were developed:

H1a: Academic self-efficacy has a positive influence on behavioural engagement. H1b: Academic self-efficacy has a positive influence on emotional engagement. H1c: Academic self-efficacy has a positive influence on cognitive engagement. $\mathrm{H} 2 \mathrm{a}$ : Perceived usefulness has a positive influence on behavioural engagement. $\mathrm{H} 2 \mathrm{~b}$ : Perceived usefulness has a positive influence on emotional engagement. $\mathrm{H} 2 \mathrm{c}$ : Perceived usefulness has a positive influence on cognitive engagement. H3a: Teaching presence has a positive influence on behavioural engagement. $\mathrm{H} 3 \mathrm{~b}$ : Teaching presence has a positive influence on emotional engagement. $\mathrm{H} 3 \mathrm{c}$ : Teaching presence has a positive influence on cognitive engagement. $\mathrm{H} 4 \mathrm{a}$ : Behavioural engagement has a positive influence on student satisfaction. H4b: Emotional engagement has a positive influence on student satisfaction. H4c: Cognitive engagement has a positive influence on student satisfaction. H5a: Behavioural engagement has a mediation effect on the effect of academic self-efficacy on student satisfaction.

H5b: Behavioural engagement has a mediation effect on the effect of perceived usefulness on student satisfaction.

H5c: Behavioural engagement has a mediation effect on the effect of teaching presence on student satisfaction.

H6a: Emotional engagement has a mediation effect on the effect of academic selfefficacy on student satisfaction.

H6b: Emotional engagement has a mediation effect on the effect of perceived usefulness on student satisfaction.

H6c: Emotional engagement has a mediation effect on the effect of teaching presence on student satisfaction.

H7a: Cognitive engagement has a mediation effect on the effect of academic selfefficacy on student satisfaction.

H7b: Cognitive engagement has a mediation effect on the effect of perceived usefulness on student satisfaction.

H7c: Cognitive engagement has a mediation effect on the effect of teaching presence on student satisfaction.

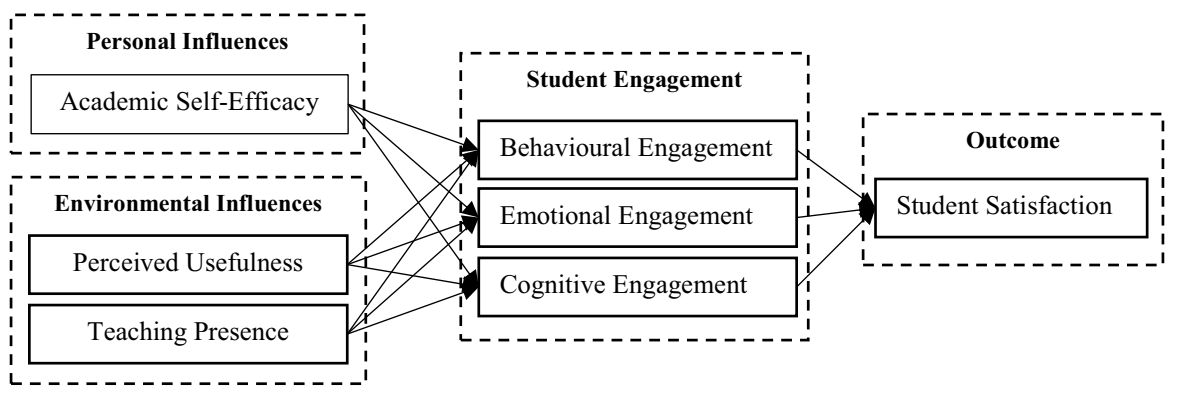

Fig. 1 The research model 


\section{Methodology}

\section{Instruments}

The online survey used in this study included demographic questions to gather data regarding the participants' age, gender, and the college in which they were enrolled. It also comprised items related to the study constructs: academic self-efficacy, perceived usefulness, teaching presence, student engagement, and student satisfaction. An academic self-efficacy scale was adopted from the Motivated Strategies for Learning Questionnaire (MSLQ), which was developed by Pintrich et al. (1993) and was adapted and validated by Cho et al. (2017) in an online learning study. The questionnaire comprised four items regarding students' success expectancy and selfefficacy (e.g. 'I 'm certain I can understand the most difficult material presented in the online course'). The perceived usefulness scale included six items that were developed by Davis (1989) and that was adapted and validated by Liaw and Huang (2013) to measure students' perceptions of online learning systems for improving their learning performance (e.g. 'I believe using online learning is effective for learning').

The teaching presence scale comprised ten items (e.g. 'The instructor clearly communicated important course topics') that were developed by Swan et al. (2008) and that was adapted and validated by Cho et al. (2017) to evaluate online students' perceptions of their instructors' instructional design and organisation, discourse facilitation, and direct instructions. The student engagement scale consisted of five items for measuring behavioural engagement (e.g. 'I follow the rules of the online class'), six items for emotional engagement (e.g. 'I like taking the online class'), and eight items for cognitive engagement (e.g. 'I check my assignment for mistakes'). This engagement scale was developed by Fredricks et al. (2004) and Fredricks et al. (2005) to evaluate children students' engagement, and Sun and Rueda (2012) adapted and validated it to evaluate graduate and undergraduate student engagement in online learning. Finally, the scale of student satisfaction scale included five items (e.g. 'Overall, I am satisfied with this online course') concerning student satisfaction with their online learning experience; it was adapted and validated by Kuo et al. (2014).

The academic self-efficacy and perceived usefulness items were rated from 1 (strongly disagree) to 7 (strongly agree) on a seven-point Likert scale, while the rest of items were rated between 1 (strongly disagree) and 5 (strongly agree) on a fivepoint Likert scale.

\section{Study context and participants}

The sample group included in this study was made up of online undergraduate students enrolled at a well-known accredited educational institution in Egypt. Students in different colleges (e.g. the college of engineering and technology) were required to continue their studies in a fully online capacity since the coronavirus outbreak 
that started in Egypt in mid-March 2020, which lasted for more than 7 weeks. The online courses had similar characteristics to each other, including online lectures, recorded videos, online learning materials, and online and offline assignments.

The majority of students $(92.4 \%)$ were aged between 16 and 24 years, while $7.6 \%$ were over 24 years. Of the 330 students, $68.8 \%$ were male and $31.2 \%$ were female. The students were enrolled in different colleges, including management and technology (45.5\%), engineering and technology (43.9\%), computing and information technology $(3.0 \%)$, international transport and logistics $(4.8 \%)$, language and communication $(2.4 \%)$, and pharmacy $(0.3 \%)$.

\section{Data collection and data analysis}

After the students completed the online learning process, they were emailed with the link of a self-reported questionnaire. To avoid any missing data, all of the questions were in a required-answer format. Out of 419 received responses, 330 were valid for data analysis. The data analysis was performed with structural equation modelling using SmartPLS 3.2.9 software to examine the direct and indirect relationships between the study variables. Furthermore, SPSS 23.0 software was used for descriptive data analysis.

\section{Results}

\section{Descriptive analysis}

The means and standard deviations for the variables are presented in Tables 1, 2 and 3. The mean scores for the variables from the seven-point Likert scale were 4.83 and 5.03, and the standard deviation scores were 1.40 and 1.63 for academic selfefficacy and perceived usefulness, respectively. The mean scores for the variables from the five-point Liker scale ranged between 3.24 and 3.79, with standard deviations ranging from 0.61 to 1.15 . These results suggest that the participants generally agreed with the survey questions.

\section{Results of the measurement model}

The study model comprised nine lower-order variables. Eight variables were with reflective indicators, namely academic self-efficacy, perceived usefulness, instructional design and organisation, discourse facilitation, direct instructions, behavioural engagement, emotional engagement, and cognitive engagement. In contrast, the student satisfaction variable was a lower-order construct with formative indicators.

\section{Reflective measurement model assessment}

Composite reliability (CR) was used to assess the internal consistency reliability of study variables, while the outer loadings of the indicators and the reflective 
Table 1 Descriptive and reflective measurement assessment results

\begin{tabular}{|c|c|c|c|c|c|c|c|}
\hline Lower-order & Higher-order & Indicators & Loadings & M & $\mathrm{SD}$ & AVE & $\mathrm{CR}$ \\
\hline \multirow{4}{*}{$\begin{array}{l}\text { Academic self-efficacy } \\
\text { (ASE) }\end{array}$} & & ASE1 & 0.711 & \multirow[t]{4}{*}{4.83} & \multirow[t]{4}{*}{1.40} & \multirow[t]{4}{*}{0.701} & \multirow[t]{4}{*}{0.903} \\
\hline & & ASE2 & 0.887 & & & & \\
\hline & & ASE3 & 0.846 & & & & \\
\hline & & ASE4 & 0.893 & & & & \\
\hline \multirow[t]{6}{*}{ Perceived usefulness (PU) } & & PU1 & 0.909 & \multirow[t]{6}{*}{5.03} & \multirow[t]{6}{*}{1.63} & \multirow[t]{6}{*}{0.815} & \multirow[t]{6}{*}{0.964} \\
\hline & & PU2 & 0.903 & & & & \\
\hline & & PU3 & 0.888 & & & & \\
\hline & & PU4 & 0.899 & & & & \\
\hline & & PU5 & 0.923 & & & & \\
\hline & & PU6 & 0.895 & & & & \\
\hline \multirow{4}{*}{$\begin{array}{l}\text { Instructional design and } \\
\text { organisation (DO) }\end{array}$} & \multirow[t]{6}{*}{ Teaching presence (TP) } & TP1 & 0.890 & \multirow[t]{4}{*}{3.79} & \multirow[t]{4}{*}{0.97} & \multirow[t]{4}{*}{0.742} & \multirow[t]{4}{*}{0.920} \\
\hline & & TP2 & 0.886 & & & & \\
\hline & & TP3 & 0.873 & & & & \\
\hline & & TP4 & 0.793 & & & & \\
\hline \multirow[t]{2}{*}{ Direct instructions (DI) } & & TP5 & 0.940 & \multirow[t]{2}{*}{3.75} & \multirow[t]{2}{*}{1.09} & \multirow[t]{2}{*}{0.885} & \multirow[t]{2}{*}{0.939} \\
\hline & & TP6 & 0.941 & & & & \\
\hline \multirow[t]{4}{*}{ Discourse facilitation (DF) } & & TP7 & 0.878 & \multirow[t]{4}{*}{3.68} & \multirow[t]{4}{*}{1.07} & \multirow[t]{4}{*}{0.766} & \multirow[t]{4}{*}{0.929} \\
\hline & & TP8 & 0.877 & & & & \\
\hline & & TP9 & 0.845 & & & & \\
\hline & & TP10 & 0.899 & & & & \\
\hline \multirow{3}{*}{$\begin{array}{l}\text { Behavioural engagement } \\
\text { (BE) }\end{array}$} & & BE1 & 0.722 & \multirow[t]{3}{*}{3.44} & 0.61 & 0.562 & 0.793 \\
\hline & & BE4 & 0.820 & & & & \\
\hline & & BE5 & 0.702 & & & & \\
\hline Emotional engagement (EE) & & EE1 & 0.879 & 3.24 & 0.97 & 0.833 & 0.961 \\
\hline & & EE2 & 0.912 & & & & \\
\hline & & EE3 & 0.912 & & & & \\
\hline & & EE4 & 0.935 & & & & \\
\hline & & EE5 & 0.924 & & & & \\
\hline Cognitive engagement (CE) & & CE1 & 0.707 & 3.64 & 0.78 & 0.540 & 0.854 \\
\hline & & CE2 & 0.759 & & & & \\
\hline & & CE3 & 0.695 & & & & \\
\hline & & CE4 & 0.816 & & & & \\
\hline & & CE5 & 0.689 & & & & \\
\hline
\end{tabular}

variables average variance extracted (AVE) were used to assess the convergent validity (Hair et al., 2017). According to Table 1, all loadings that exceeded the threshold of 0.708 were retained (Hair et al., 2017). Indicators with low loadings $(<0.40)$ were subsequently dropped. The outer loadings of BE5, CE1, CE3, and CE5, which were slightly below 0.708 , were retained because the average extracted variance was greater than 0.50 (Hair et al., 2017). All eight of the reflective variables met the threshold values for $\mathrm{CR}$ and $\mathrm{AVE}$; the $\mathrm{CR}$ values were 
Table 2 HTMT results

\begin{tabular}{lllllll}
\hline & 1 & 2 & 3 & 4 & 5 & 6 \\
\hline 1. ASE & & & & & & \\
2. BE & 0.665 & & & & \\
3. CE & 0.500 & 0.644 & & & & \\
4. EE & 0.737 & 0.664 & 0.573 & & & \\
5. TP & 0.699 & 0.637 & 0.536 & 0.647 & & \\
6. PU & 0.799 & 0.572 & 0.520 & 0.784 & 0.660 & \\
\hline
\end{tabular}

$A S E$ academic self-efficacy, $P U$ perceived usefulness, $T P$ teaching presence, $B E$ behavioural engagement, $E E$ emotional engagement, $C E$ cognitive engagement, $S S$ student satisfaction

Table 3 Formative measurement results

\begin{tabular}{lllllllll}
\hline Variable & Items & $\mathrm{M}$ & $\mathrm{SD}$ & $\beta$ & Weights & VIF & $t$-value & $p$-value \\
\hline Student satisfaction (SS) & SS2 & \multirow{2}{*}{3.44} & \multirow{2}{*}{1.15} & 0.861 & 0.335 & 3.879 & $4.382^{*}$ & 0.000 \\
& SS3 & & & & 0.044 & 3.097 & 0.731 & 0.465 \\
& SS4 & & & & 0.312 & 2.428 & $5.245^{*}$ & 0.000 \\
& SS5 & & & & 0.430 & 2.270 & $5.657^{*}$ & 0.000 \\
\hline
\end{tabular}

$t>1.96 ;{ }^{*} p<0.05$

greater than 0.70 and the AVEs exceeded the threshold value of 0.50 (Hair et al., 2017). These results demonstrate that the reflective variables of the research model met the reliability and convergent validity requirements.

The heterotrait-monotrait ratios (HTMTs) were inspected for the discriminant validity assessment (Henseler et al., 2015). As can be seen in Table 2, all HTMT values were lower than 0.85 and 0.90 (Gold et al., 2001; Kline, 2015), which confirms that discriminant validity was established.

\section{Formative measurement assessment}

Convergent validity, collinearity issue, and significance and relevance were inspected to assess the formative indicators (Hair et al., 2017). Table 3 shows that the formative construct student satisfaction had a yield path coefficient $(\beta)$ of 0.861 , which, being greater than 0.70 , indicates that the formatively measured construct had sufficient degrees of convergent validity (Klassen \& Whybark, 1999). Moreover, the variance inflation factor (VIF) values were below the threshold values of 5 (Hair et al. 2017), which indicates that collinearity did not reach critical levels in the formative construct, and therefore, was not an issue for PLS path model estimation. Finally, all formative indicators except SS3 were found to be significant ( $p$-values $<0.05$ ). However, since all outer loadings were above 0.50 and were significant, with t-values of $>1.645$, as shown in Table 4 , SS3 was retained (Hair et al., 2017). 


\section{Results of the structural model}

Before assessing the structural model, the collinearity between study variables was evaluated to ensure that the structural model did not include any lateral collinearity issue (Hair et al., 2017). Table 5 shows that all inner VIF values were below 5 (Hair et al., 2017), indicating that collinearity among the predictor constructs was not a concern in the structural model. Next, we assessed the structural model by computing the beta $(\beta)$, t-values, and $R^{2}$ using a 5000 sampling bootstrapping technique (Hair et al., 2017). Finally, the predictive relevance $\left(Q^{2}\right)$ and effect sizes $\left(\mathrm{f}^{2}\right)$ were inspected.

As can be seen in Table 5, behavioural engagement was predicted by academic self-efficacy $(\beta=0.288, t=3.838, p<0.05)$ and teaching presence $(\beta=0.280$ $, t=4.232, p<0.05)$. Emotional engagement was predicted by academic self-efficacy $(\beta=0.204, t=3.320, p<0.05)$, perceived usefulness $(\beta=0.469, t=7.521$, $p<0.05)$, and teaching presence $(\beta=0.203, t=4.278, \quad p<0.05)$. Cognitive engagement, however, was only predicted by perceived usefulness $(\beta=0.186$ $, t=2.502, p<0.05)$ and teaching presence $(\beta=0.305, t=3.873, p<0.05)$, and student satisfaction was only predicted by behavioural engagement $(\beta=0.111$ $, t=2.895, p<0.05)$ and emotional engagement $(\beta=0.755, t=23.722, p<0.05)$, but not by cognitive engagement. In short, all direct hypotheses were supported except H1c, H2a, and H4c, as shown in Fig. 2.

With regard to the $R^{2}$ values of endogenous variables, exogenous variables explained $33.2 \%$ of variances in behavioural engagement, $61.9 \%$ in emotional engagement, and $28 \%$ in cognitive engagement. Meanwhile, the behavioural, emotional, and cognitive engagement variables explained $72.9 \%$ of the variance in student satisfaction. As was suggested by Chin (1998), $R^{2}$ values of 0.19 , 0.33 , and 0.67 are considered to be weak, moderate, and substantial, respectively. Therefore, the $R^{2}$ values of behavioural engagement, emotional engagement, cognitive engagement, and student satisfaction met the acceptable levels of predictive accuracy (Chin, 1998; Cohen, 1988).

The effect sizes $\left(\mathrm{f}^{2}\right)$, of which rely on changes in $\mathrm{R}^{2}$ values, were assessed (Hair et al., 2017). As suggested by Cohen (1988), the values of 0.02, 0.15, and 0.35 are considered to be small, medium, and large effect sizes, respectively. Table 5 presents the $\mathrm{f}^{2}$ results according to effect sizes: one relationship (large), one (medium), seven (small), and three (had no effect).

Table 4 Outer loadings of formative indicators

\begin{tabular}{llll}
\hline Variable & Items & Loadings & $p$-value \\
\hline Student satisfaction (SS) & SS2 & $0.914^{*}$ & 0.000 \\
& SS3 & $0.816^{*}$ & 0.000 \\
& SS4 & $0.864^{*}$ & 0.000 \\
& SS5 & $0.902^{*}$ & 0.000 \\
\hline
\end{tabular}

$t>1.645 ;{ }^{*} p<0.05$ 


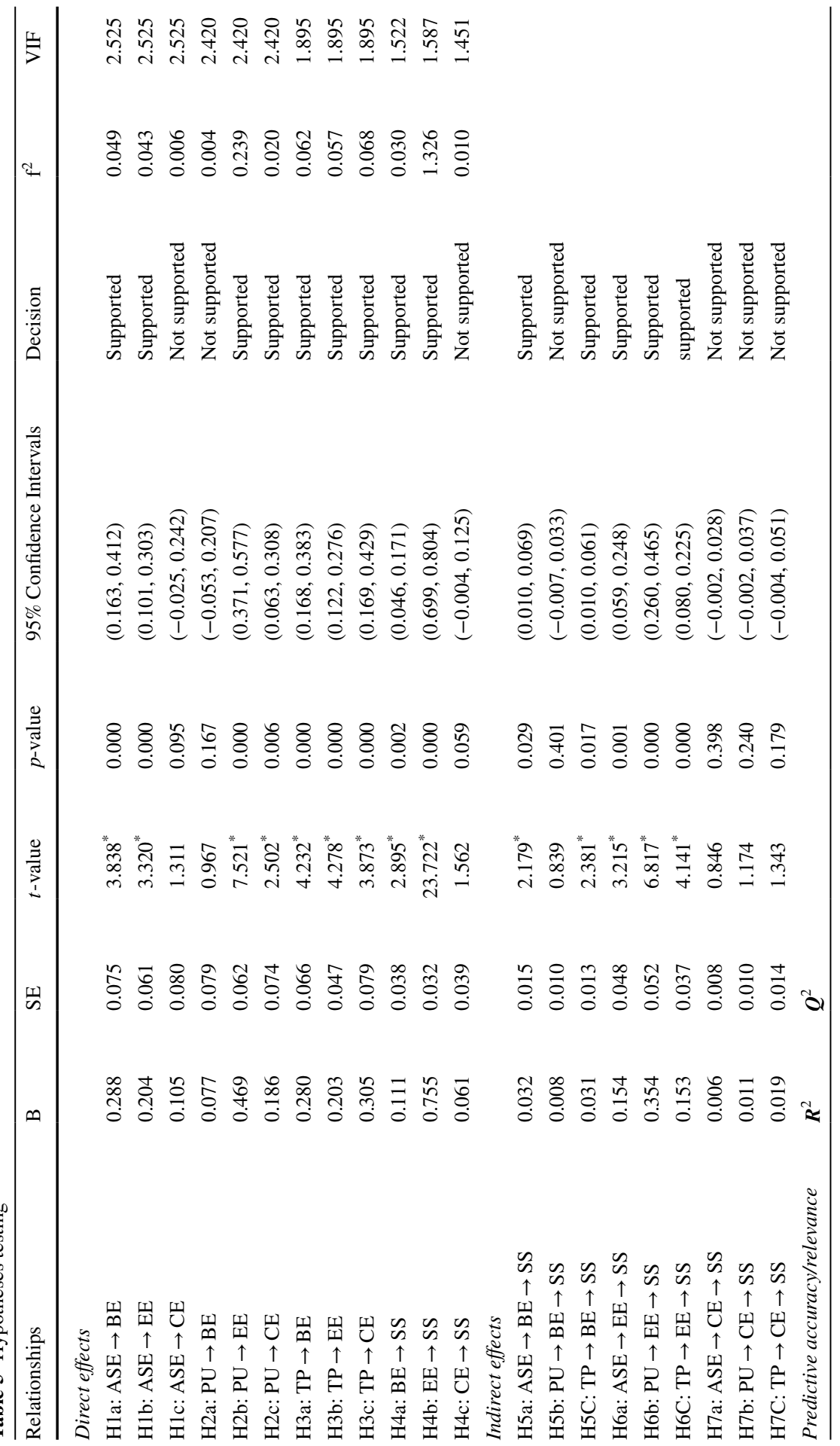




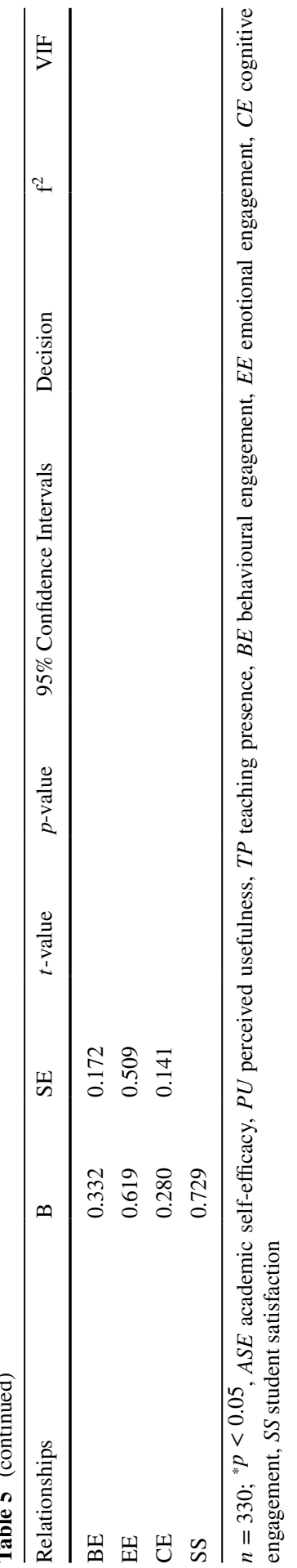




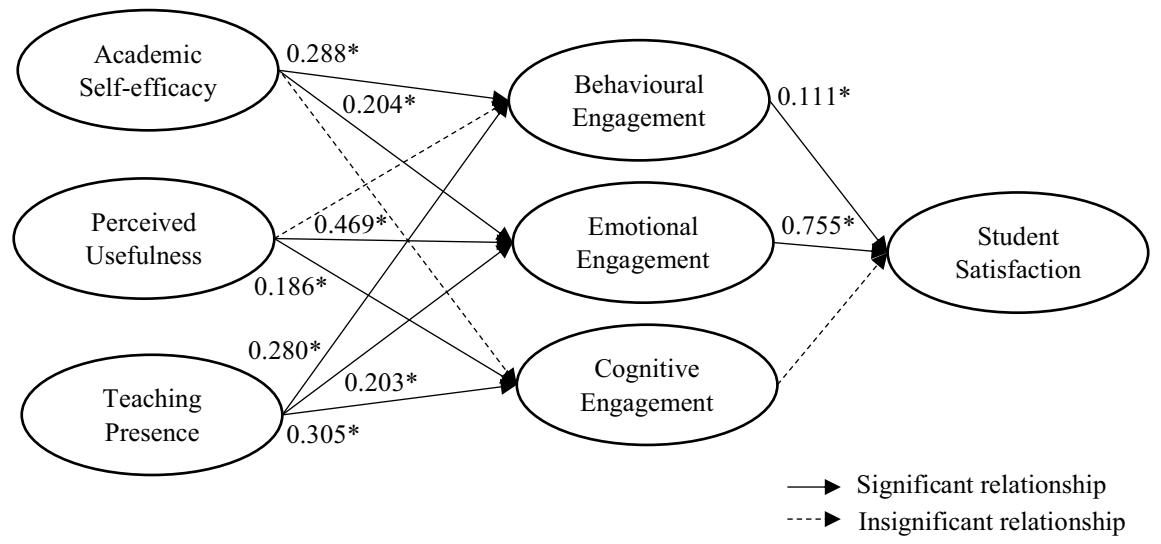

Fig. 2 Standardised path coefficients $n=330 ; * p<0.05$

The blindfolding technique was implemented to assess the predictive relevance, which is only used for reflective endogenous constructs (Hair et al., 2017). According to Table 5, the $\mathrm{Q}^{2}$ values of behavioural engagement, emotional engagement, and cognitive engagement were above zero, which reveals that the model had predictive relevance for the outcome variables (Geisser, 1974; Hair et al., 2017). More specifically, emotional engagement had the highest $\mathrm{Q}^{2}$ values, followed by behavioural engagement and, finally, cognitive engagement.

\section{Mediation assessment}

To assess the mediating effects, the significance of the indirect effect was examined; the bias-corrected and accelerated bootstrapping technique were used for this assessment (Hair et al., 2017). As suggested by Hair et al. (2017), the significant indirect effects are achieved at t-values $>1.96$ and p-values $<0.05$. Table 5 illustrates that the results indicated that behavioural engagement only mediated the effects of academic self-efficacy $(t=2.179, p<0.05)$ and teaching presence $(t=2.381, p<0.05)$ on student satisfaction. Moreover, emotional engagement mediated the effects of academic self-efficacy $(t=3.215, p<0.05)$, perceived usefulness $(t=6.817, p<0.05)$, and teaching presence $(t=4.141, p<0.05)$ on student satisfaction. The bootstrap confidence intervals of these results did not include zero, indicating the inclusion of mediation effects (Kristopher $\mathrm{J}$. Preacher \& Hayes, 2004, K. J. Preacher \& Hayes, 2008). Contrary to our expectations, behavioural engagement did not mediate the effect of perceived usefulness $(t=0.839, p>0.05)$ on student satisfaction. Furthermore, cognitive engagement had no mediation role in the effects of academic self-efficacy $(t=0.846$, $p>0.05)$, perceived usefulness $(t=1.174, p>0.05)$, supported except H5b, H7a, H7b, H7c. 


\section{Discussion}

This study revealed that online student engagement can be modelled by different learning components, including the students themselves, their online course instructors, and the supportive learning systems. Primarily, the findings of this study demonstrated that academic self-efficacy has a significant positive effect on behavioural and emotional engagement. These results imply that increasing students' confidence in their academic competence contributes to heightening their participation in online learning activities and their positive attitudes towards the online learning environment. These results are in line with SCT, which holds that the self-efficacy of individuals acts as a personal and motivational factor that impacts their actions and behaviours (Bandura, 1986, 1997; Schunk \& Mullen, 2012).

The second noteworthy finding from this study is that the usefulness of online learning systems has a meaningful positive effect on emotional and cognitive engagement, which implies that the more students perceive that online learning systems can improve their learning performance, the more they show positive attitudes towards online learning; they will also spend more effort to understand and master learning materials. Perceived usefulness was found to be the most significant factor for supporting students' emotional engagement $(\beta=0.469$, $p<0.05$ ), which emphasises the importance of the quality and functionality of online learning systems in order to increase the emotional and cognitive engagement of online students. Consistent with SCT, this study found that online student behaviour is affected by supportive technological environments (Piccoli et al., 2001). On the contrary, however, this study showed that perceived usefulness had an insignificant effect on behavioural engagement. One explanation of this result is that online learning was the only method available to students to complete their studies during the lockdown brought about by the COVID-19 pandemic, which means that their participation in online learning activities did not depend on their perceptions of its usefulness.

Third, the current study found that teaching presence, based on instructional design and organisation, discourse facilitation, and direct instruction, had a positive direct effect on all engagement dimensions, especially cognitive engagement $(\beta=0.305, p<0.05)$. These findings illustrate that the more important students consider the role of online course instructors for designing and organising the online course content, supporting them, and providing them with the required guidance and feedback, the more they will engage with online learning on behavioural, emotional, and cognitive levels. These findings are in line with the SCT perspective that individuals' behaviours are affected by environmental influences (e.g. the learning climate) (Bandura, 1986).

The fourth main revelation of this study established that the engagement of online students produces significant positive effects on their satisfaction with online learning, which implies that students with higher behavioural and emotional engagement are more satisfied with online learning. Furthermore, the results demonstrated that emotional engagement was the most important predictor 
of student satisfaction with online learning $(\beta=0.755, p<0.05)$. Therefore, the findings show that students who participate in online learning activities, especially those who have positive attitudes towards online learning, report higher satisfaction levels. The study did, however, fail to find a relationship between cognitive engagement and student satisfaction. This finding may be explained by that online learning was essential and there was not any alternative way for students to complete their academic semester during the lockdown, so they dedicated their time and effort for their learning, regardless their satisfaction with their online learning experience.

Finally, the results revealed an indirect influence of academic self-efficacy and teaching presence on student satisfaction through behavioural and emotional engagement. Moreover, emotional engagement mediated the relationship between perceived usefulness and student satisfaction. These findings confirm the importance of designing online learning systems that include motivational features such as digital badges, progression alerts, and interesting tasks and assignments with instant feedback. In addition to introducing challenging quizzes, they should include different levels which allow students to select what is the most suitable option for their capabilities. These motivational aspects support students' academic self-efficacy which helps in fostering their behavioural and emotional engagement which, in turn, promote their satisfaction with online learning.

Furthermore, to support the behavioural and emotional engagement and overall satisfaction of online students, the main role of the online course instructor must be considered. Instructors have multidimensional roles in online learning since they act as course facilitators, course monitors, intellectual simulators, and social supporters for online students (Eom \& Ashill, 2016). In addition to the results revealed from the direct effects which demonstrate that online course instructors perform an essential and influential role on students' behavioural, emotional, and cognitive engagement with online learning, the indirect effects report that online course instructors can also support students' satisfaction with online learning through encouraging their behavioural and emotional engagement. As articulated by Dev (1997), course instructors can simulate students' motivation through several ways including providing them with positive feedback and responses to their questions which, thereby, develop students' sense of competence. Furthermore, instructors define learning goals for the course and create assignments and course materials that challenge and simulate students' intellectual effort.

On the whole, for the purpose of increasing students' emotional engagement and satisfaction in online learning environments, the usefulness of online learning systems must be considered. The more students perceive that online learning systems improve their learning performance, the more they adopt positive attitudes towards online learning, and the more they become satisfied with online learning. To sum up, it is important to consider the dynamic relationship between students' motivation and engagement with online learning, the quality of online course design, and the facilitation role played by online course instructors (Eom \& Ashill, 2016). These elements cooperate together to deliver an effective online learning process as they influence student behaviour and outcomes. 
Contrary to our expectations, this study found that cognitive engagement had no mediation effect on the relationships between academic self-efficacy, perceived usefulness, and teaching presence and student satisfaction. This may be explained by that as online learning requires students to invest more time and effort to their learning (Kim et al., 2018) they were challenged to successfully continue their academic semester, regardless their doubts about their academic confidence, the usefulness of the online learning system, the presence of their instructors, and their satisfaction with the online learning experience.

In short, the COVID-19 pandemic has provided an opportunity for higher education institutions in Egypt to apply a real simulation of a semi-complete online learning process to undergraduate students. The findings of the current study reveal that students were satisfied with their online learning experience, which implies that the implementation of online learning in the educational process would be accepted by most students. The results of this study also emphasise the importance of online learning systems as an essential aspect of higher education in Egypt, especially for the improvement of teaching and learning quality. Therefore, we consider that the pandemic has actually given rise to long-term improvements for Egypt's higher education system. As it is unknown how long this pandemic will remain, higher education institutions, online course instructors, and instructional designers should consider the findings of this study in their quest to better understand how to foster the behavioural, emotional, and cognitive engagement of online students and how best to promote their satisfaction with online learning.

\section{Conclusion and study limitations}

This study investigated the perceptions of Egypt's higher education students with regard to their engagement and satisfaction with their online learning experience during the COVID-19 lockdown. Based on SCT, the study examined the influence of students' academic self-efficacy and perceived usefulness, as well as teaching presence, on their engagement and satisfaction with online learning. In other words, this study investigates the impact of students' personal factors and the online learning environment, especially with regard to teaching presence and the usefulness of online learning systems, on student behaviour and, in turn, outcomes. The findings exposed the significant role played by the students' behavioural and emotional engagement and its contribution in supporting student satisfaction outcomes. Furthermore, they illustrate how online students' behaviour can be modelled by considering their personal and environmental influences. Therefore, this study provides a theoretical contribution that will help researchers to better understand the factors that influence the engagement and satisfaction of online students in Egyptian higher education. Furthermore, it will help the higher education institutions formulate plans for continuing with online learning, either until the end of the pandemic or as a part of their future educational process. Finally, this study spotlights the role of online learning engagement in improving the educational process in universities and demonstrates that it is essential to consider the impact of the behavioural, emotional, and cognitive engagement of online students in attaining satisfaction outcome. 
This study does, however, have several limitations that present the need for future research. First, the study data were collected from one higher education institution and in one developing country, which makes its findings difficult to generalise. Therefore, further research to investigate the engagement and satisfaction of online students at different public and private Egyptian universities, as well as at universities in another developing countries, is necessary. Second, the cross-sectional survey method was used in this study, which means that self-reported measures were used to capture student perceptions. Future studies should employ longitudinal and qualitative research designs to uncover a better understanding of each engagement dimension and student satisfaction levels. Finally, the current study only concentrated on the engagement of online students and its impact on student satisfaction. Hence, further research is needed to examine the impact of online student engagement on their cognitive achievements such as academic performance and learning persistence.

Acknowledgements Not applicable.

Author contributions All authors contributed to the study conception and design. Material preparation, data collection and analysis were performed by Ghada, Nor Hasliza, and Ramayah. The first draft of the manuscript was written by Ghada, and all authors commented on previous versions of the manuscript. All authors read and approved the final manuscript.

Funding Not applicable.

\section{Declarations}

Conflict of interest Not applicable.

\section{References}

Ab Rahman, R., Ahmad, S., \& Hashim, U. R. (2019). A Study on gamification for higher education students' engagement towards education 4.0. In V. Piuri, V. E. Balas, S. Borah, \& S. S. Syed Ahmad (Eds.), Intelligent and interactive computing, Singapore, 2019 (pp. 491-502): Springer, Singapore. doi:https://doi.org/10.1007/978-981-13-6031-2_5.

Adel, R. (2017). Manage perceived e-learning quality in Egyptian context. Total Quality Management \& Business Excellence, 28(5-6), 600-613. https://doi.org/10.1080/14783363.2015.1103174

Al-Samarraie, H., Teng, B. K., Alzahrani, A. I., \& Alalwan, N. (2018). E-learning continuance satisfaction in higher education: a unified perspective from instructors and students. Studies in Higher Education, 43(11), 2003-2019. https://doi.org/10.1080/03075079.2017.1298088

Ali, A., \& Ahmad, I. (2011). Key factors for determining student satisfaction in distance learning courses: A study of Allama Iqbal Open University. Contemporary Educational Technology, 2(2), 118-134, doi:https://doi.org/10.30935/cedtech/6047.

Alqurashi, E. (2019). Predicting student satisfaction and perceived learning within online learning environments. Distance Education, 40(1), 133-148. https://doi.org/10.1080/01587919.2018.1553562

Anderson, T., Rourke, L., Garrison, R., \& Archer, W. (2001). Assessing teaching presence in a computer conferencing context. Online Learning, 5(2), 1-17, doi:https://doi.org/10.24059/olj.v5i2.1875

Bandura, A. (1977). Self-efficacy: Toward a unifying theory of behavioral change. Psychological Review, 84(2), 191. https://doi.org/10.1037/0033-295X.84.2.191

Bandura, A. (1986). Social foundations of thought and action. In D. F. Marks (Ed.), The Health Psychology Reader (pp. 23-28). SAGE Publications. 
Bandura, A. (1997). Self-efficacy: The exercise of control (Self-efficacy: The exercise of control.). New York, NY, US: Worth Publishers.

Bolliger, D. U., \& Halupa, C. (2018). Online student perceptions of engagement, transactional distance, and outcomes. Distance Education, 39(3), 299-316. https://doi.org/10.1080/01587919.2018.14768 45

Burch, G. F., Burch, J. J., \& Womble, J. (2017). Student engagement: An empirical analysis of the effects of implementing mandatory web-based learning systems. Organization Management Journal, 14(2), 116-125. https://doi.org/10.1080/15416518.2017.1325349

Chin, W. W. (1998). The partial least squares approach to structural equation modeling. In G. A. Marcoulides (Ed.), Modern methods for business research (pp. 295-336). Psychology Press.

Cho, M. H., Kim, Y., \& Choi, D. (2017). The effect of self-regulated learning on college students' perceptions of community of inquiry and affective outcomes in online learning. The Internet and Higher Education, 34, 10-17. https://doi.org/10.1016/j.iheduc.2017.04.001

Coates, H. (2006). Student engagement in campus-based and online education: University connections. Routledge.

Cohen, J. (1988). Statistical power analysis for the behavioral sciences (2nd ed.). . Academic Press.

Davis, F. D. (1989). Perceived usefulness, perceived ease of use, and user acceptance of information technology. MIS Quarterly, 13(3), 319-340. https://doi.org/10.2307/249008

Debourgh, G. A. (1999). Technology is the tool, teaching is the task: Student satisfaction in distance learning. In J. D. Price, J. Willis, D. A. Willis, M. Jost, \& S. Boger-Mehall (Eds.), Society for information technology \& teacher education international conference, 1999 (pp. 131-137). Waynesville, NC USA: Association for the Advancement of Computing in Education (AACE)

Dev, P. C. (1997). Intrinsic motivation and academic achievement: What does their relationship imply for the classroom teacher? Remedial and Special Education, 18(1), 12-19. https://doi.org/10.1177/ 074193259701800104

Diab, G. M. A. E. H., \& Elgahsh, N. F. (2020). E-learning during COVID-19 pandemic: Obstacles faced nursing students and its effect on their attitudes while applying it. American Journal of Nursing, 9(4), 300-314, doi: https://doi.org/10.11648/j.ajns.20200904.33.

El-Khouly, M. M. (2018). Egypt. In A. S. Weber \& S. Hamlaoui (Eds.), E-learning in the Middle East and North Africa (MENA) region (pp. 67-92). Springer International Publishing.

El-Seoud, S., Taj-Eddin, I., Seddiek, N., Ghenghesh, P., \& El-Khouly, M. (2014). The impact of e-learning on Egyptian higher education and its effect on learner's motivation: A case study. Computer Science and Information Technology, 2(3), 179-187. https://doi.org/10.13189/csit.2014.020307

El Gamal, S., \& Abd El Aziz, R. (2012). Improving higher education in Egypt through e-learning programs: HE students and senior academics perspective. International Journal of Innovation in Education, 1(4), 335-361. https://doi.org/10.1504/IJIIE.2012.052738

Eom, S. B., \& Ashill, N. (2016). The determinants of students' perceived learning outcomes and satisfaction in university online education: An update. Decision Sciences Journal of Innovative Education, 14(2), 185-215. https://doi.org/10.1111/dsji.12097

Findlay-Thompson, S., \& Mombourquette, P. (2014). Evaluation of a flipped classroom in an undergraduate business course. Business Education \& Accreditation, 6(1), 63-71.

Fisher, R., Perényi, Á., \& Birdthistle, N. (2018). The positive relationship between flipped and blended learning and student engagement, performance and satisfaction. Active Learning in Higher Education. https://doi.org/10.1177/1469787418801702

Fredricks, J. A., Blumenfeld, P. C., \& Paris, A. H. (2004). School engagement: Potential of the concept, state of the evidence. Review of Educational Research, 74(1), 59-109. https://doi.org/10.3102/ 00346543074001059

Fredricks, J. A., Moore, K. A., \& Lippman, L. H. (2005). School engagement. In K. A. Moore, \& L. H. Lippman (Eds.), What do children need to flourish?: Conceptualizing and measuring indicators of positive development (Vol. 3, pp. 305-321). New York, NY: Springer Science \& Business Media.

Geisser, S. (1974). A predictive approach to the random effect model. Biometrika, 61(1), 101-107. https://doi.org/10.1093/biomet/61.1.101

Gold, A. H., Malhotra, A., \& Segars, A. H. (2001). Knowledge management: An organizational capabilities perspective. Journal of Management Information Systems, 18(1), 185-214. https://doi.org/10. 1080/07421222.2001.11045669

Gray, J. A., \& DiLoreto, M. (2016). The effects of student engagement, student satisfaction, and perceived learning in online learning environments. International Journal of Educational Leadership Preparation, 11(1), 1-20. 
Gunuc, S., \& Kuzu, A. (2015). Confirmation of campus-class-technology model in student engagement: A path analysis. Computers in Human Behavior, 48, 114-125. https://doi.org/10.1016/j.chb.2015. 01.041

Hair, J. F., Hult, G. T. M., Ringle, C., \& Sarstedt, M. (2017). A primer on partial least squares structural equation modeling (PLS-SEM). Sage publications.

Henrie, C. R., Halverson, L. R., \& Graham, C. R. (2015). Measuring student engagement in technologymediated learning: A review. Computers \& Education, 90, 36-53. https://doi.org/10.1016/j.compe du.2015.09.005

Henseler, J., Ringle, C. M., \& Sarstedt, M. (2015). A new criterion for assessing discriminant validity in variance-based structural equation modeling. Journal of the Academy of Marketing Science, 43(1), 115-135. https://doi.org/10.1007/s11747-014-0403-8

Hew, K. F. (2016). Promoting engagement in online courses: What strategies can we learn from three highly rated MOOCS. British Journal of Educational Technology, 47(2), 320-341. https://doi.org/ 10.1111/bjet.12235

Hu, P. J. H., \& Hui, W. (2012). Examining the role of learning engagement in technology-mediated learning and its effects on learning effectiveness and satisfaction. Decision Support Systems, 53(4), 782792. https://doi.org/10.1016/j.dss.2012.05.014

Hui, Y. K., Li, C., \& Qian, S. (2019). Learning engagement via promoting situational interest in a blended learning environment. Journal of Computing in Higher Education, 31(2), 408-425. https://doi.org/ 10.1007/s12528-019-09216-Z

Jan, S. K. (2015). The relationships between academic self-efficacy, computer self-efficacy, prior experience, and satisfaction with online learning. American Journal of Distance Education, 29(1), 30-40. https://doi.org/10.1080/08923647.2015.994366

Johnson, N., Veletsianos, G., \& Seaman, J. (2020). US Faculty and administrators' experiences and approaches in the early weeks of the COVID-19 pandemic. Online Learning, 24(2), 6-21.

Jung, Y., \& Lee, J. (2018). Learning engagement and persistence in massive open online courses (MOOCS). Computers \& Education, 122, 9-22. https://doi.org/10.1016/j.compedu.2018.02.013

Kamel, S., \& Hussein, M. (2002). The emergence of e-commerce in a developing nation. Benchmarking: An International Journal, 10(2), 146-153, doi:https://doi.org/10.1108/14635770210421818.

Kim, D., Yoon, M., Jo, I. H., \& Branch, R. M. (2018). Learning analytics to support self-regulated learning in asynchronous online courses: A case study at a women's university in South Korea. Computers \& Education, 127, 233-251. https://doi.org/10.1016/j.compedu.2018.08.023

Klassen, R. D., \& Whybark, D. C. (1999). The impact of environmental technologies on manufacturing performance. Academy of Management Journal, 42(6), 599-615. https://doi.org/10.5465/256982

Kline, R. B. (2015). Principles and practice of structural equation modeling (4th ed.). . Guilford Publications.

Kuo, Y. C., Walker, A. E., Schroder, K. E., \& Belland, B. R. (2014). Interaction, Internet self-efficacy, and self-regulated learning as predictors of student satisfaction in online education courses. The Internet and Higher Education, 20, 35-50. https://doi.org/10.1016/j.iheduc.2013.10.001

LaRose, R., \& Eastin, M. S. (2004). A social cognitive theory of Internet uses and gratifications: Toward a new model of media attendance. Journal of Broadcasting \& Electronic Media, 48(3), 358-377. https://doi.org/10.1207/s15506878jobem4803_2

Lassoued, Z., Alhendawi, M., \& Bashitialshaaer, R. (2020). An exploratory study of the obstacles for achieving quality in distance learning during the COVID-19 pandemic. Education Sciences, 10(9), 232. https://doi.org/10.3390/educsci10090232

Liaw, S. S., \& Huang, H. M. (2013). Perceived satisfaction, perceived usefulness and interactive learning environments as predictors to self-regulation in e-learning environments. Computers \& Education, 60(1), 14-24. https://doi.org/10.1016/j.compedu.2012.07.015

Ma, J., Han, X., Yang, J., \& Cheng, J. (2015). Examining the necessary condition for engagement in an online learning environment based on learning analytics approach: The role of the instructor. The Internet and Higher Education, 24, 26-34. https://doi.org/10.1016/j.iheduc.2014.09.005

Mahmoud, S. (2020). "Higher education" is a safe transit in the Corona crisis ... and "distance learning" is another face for universities. http://gate.ahram.org.eg/News/2403717.aspx. Accessed 31 Aug 2020.

Mai, S. (2020). Egyptian universities launch "distance education” application. https://see.news/egyptianuniversities-launches-distance-education-application/. Accessed 17 Aug 2022.

Manwaring, K. C., Larsen, R., Graham, C. R., Henrie, C. R., \& Halverson, L. R. (2017). Investigating student engagement in blended learning settings using experience sampling and structural 
equation modeling. The Internet and Higher Education, 35, 21-33. https://doi.org/10.1016/j.iheduc.2017.06.002

Martin, F., Wang, C., \& Sadaf, A. (2018). Student perception of helpfulness of facilitation strategies that enhance instructor presence, connectedness, engagement and learning in online courses. The Internet and Higher Education, 37, 52-65. https://doi.org/10.1016/j.iheduc.2018.01.003

MCIT (2009). Five-year achievement report. http://www.mcit.gov.eg/Upcont/Documents/ELCC2 010222143348.pdf. Accessed 6 Sept 2020.

MCIT (2015). Measuring the digital society in Egypt: internet at a glance. http://www.mcit.gov.eg/ Upcont/Documents/Publications_1272015000_Measuring_the_Digital_Society_in_Egypt_12_. pdf. Accessed 1 Jan 2019.

MCIT (2020a). Egypt among Top 10 improvers in digital inclusion in 2020. https://mcit.gov.eg/en/ Media_Center/Press_Room/Press_Releases/57192. Accessed 29 Feb 2021.

MCIT (2020b). ICT bulletin indicators. https://mcit.gov.eg/Upcont/Documents/Publications_33202 1000_ICT_\%20Indicators_Quarterly_Bulletin_Q3_2020_English.pdf. Accessed 2 Feb 2021.

MCIT (2020c). ICT indicators in brief. https://mcit.gov.eg/Upcont/Documents/Publications_23202 1000_ICT_Indicators_in_Brief_December_2020_02032021.pdf. Accessed 2 Feb 2021.

MOHESR (2016). Newsletter 2016, official report for the Egyptian Ministry Of Higher Education. http://portal.mohesr.gov.eg/en-us/Pages/research-studies.aspx. Accessed 17 Aug 2020.

MOHESR (2017). Higher education in numbers between 2014-2017. http://portal.mohesr.gov.eg/enus/Pages/Higher-education-in-numbers.aspx. Accessed 6 Sept 2020.

Murillo-Zamorano, L. R., López Sánchez, J. Á., \& Godoy-Caballero, A. L. (2019). How the flipped classroom affects knowledge, skills, and engagement in higher education: Effects on students' satisfaction. Computers \& Education, 141, 103608. https://doi.org/10.1016/j.compedu.2019. 103608

Oncu, S., \& Cakir, H. (2011). Research in online learning environments: Priorities and methodologies. Computers \& Education, 57(1), 1098-1108. https://doi.org/10.1016/j.compedu.2010.12. 009

Piccoli, G., Ahmad, R., \& Ives, B. (2001). Web-Based virtual learning environments: A research framework and a preliminary assessment of effectiveness in basic it skills training. MIS Quarterly, 25(4), 401-426. https://doi.org/10.2307/3250989

Pintrich, P. R., Smith, D. A., Garcia, T., \& McKeachie, W. J. (1993). Reliability and predictive validity of the Motivated Strategies for Learning Questionnaire (MSLQ). Educational and Psychological Measurement, 53(3), 801-813. https://doi.org/10.1177/0013164493053003024

Preacher, K. J., \& Hayes, A. F. (2004). SPSS and SAS procedures for estimating indirect effects in simple mediation models. Behavior Research Methods, Instruments, \& Computers, 36(4), 717-731. https:// doi.org/10.3758/BF03206553

Preacher, K. J., \& Hayes, A. F. (2008). Asymptotic and resampling strategies for assessing and comparing indirect effects in multiple mediator models. Behavior Research Methods, 40(3), 879-891. https:// doi.org/10.3758/BRM.40.3.879

Rashid, T., \& Asghar, H. M. (2016). Technology use, self-directed learning, student engagement and academic performance: Examining the interrelations. Computers in Human Behavior, 63, 604-612. https://doi.org/10.1016/j.chb.2016.05.084

Reschly, A. L., Appleton, J. J., \& Pohl, A. (2008). Best practices in fostering student engagement. In A. Thomas, \& J. Grimes (Eds.), Best practices in school psychology: Student level services (6th ed.). (pp. 37-50). Bethesda, MD: National Association of School Psychologists.

Reschly, A. L., \& Christenson, S. L. (2012). Jingle, jangle, and conceptual haziness: evolution and future directions of the engagement construct. In S. L. Christenson, A. L. Reschly, \& C. Wylie (Eds.), Handbook of research on student engagement (pp. 3-19). Springer.

Schunk, D. H., \& Mullen, C. A. (2012). Self-efficacy as an engaged learner. In S. L. Christenson, A. L. Reschly, \& C. E. Wylie (Eds.), Handbook of research on student engagement (pp. 219-235). Springer.

SCU (2018). The national E-learning center. http://scu.eg/pages/nelc. Accessed 31 Aug 2020.

Shea, P., \& Bidjerano, T. (2009). Community of inquiry as a theoretical framework to foster "epistemic engagement" and "cognitive presence" in online education. Computers \& Education, 52(3), 543553. https://doi.org/10.1016/j.compedu.2008.10.007

Sobaih, A. E. E., Hasanein, A. M., \& Abu Elnasr, A. E. (2020). Responses to COVID-19 in higher education: Social media usage for sustaining formal academic communication in developing countries. Sustainability, 12(16), 6520. https://doi.org/10.3390/su12166520 
Sun, J. C. Y., \& Rueda, R. (2012). Situational interest, computer self-efficacy and self-regulation: Their impact on student engagement in distance education. British Journal of Educational Technology, 43(2), 191-204. https://doi.org/10.1111/j.1467-8535.2010.01157.x

Swan, K., Shea, P., Richardson, J., Ice, P., Garrison, D. R., Cleveland-Innes, M., et al. (2008). Validating a measurement tool of presence in online communities of inquiry. E-Mentor, 2(24), 1-12.

Thongmak, M. (2018). Raising students' cognitive engagement intention in a preliminary is course using gamification. In A. Tjoa, M. Raffai, P. Doucek, \& N. Novak (Eds.), Research and practical issues of enterprise information systems, Cham, September 18-19 2018 (Vol. 327, pp. 81-95). Poznan, Poland: Springer. doi:https://doi.org/10.1007/978-3-319-99040-8_7.

UNESCO (2020). COVID-19 educational disruption and response. https://en.unesco.org/news/covid-19educational-disruption-and-response. Accessed 17 Aug 2020.

Vayre, E., \& Vonthron, A. M. (2017). Psychological engagement of students in distance and online learning: Effects of self-efficacy and psychosocial processes. Journal of Educational Computing Research, 55(2), 197-218. https://doi.org/10.1177/0735633116656849

Wang, S. L., \& Lin, S. S. (2007). The application of social cognitive theory to web-based learning through NetPorts. British Journal of Educational Technology, 38(4), 600-612. https://doi.org/10. $1111 / \mathrm{j} .1467-8535.2006 .00645 . \mathrm{x}$

Wotto, M. (2020). The future high education distance learning in Canada, the United States, and France: Insights from before COVID-19 secondary data analysis. Journal of Educational Technology Systems, 49(2), 262-281. https://doi.org/10.1177/0047239520940624

Wu, J.-H., Tennyson, R. D., \& Hsia, T.-L. (2010). A study of student satisfaction in a blended e-learning system environment. Computers \& Education, 55(1), 155-164. https://doi.org/10.1016/j.compedu. 2009.12.012

Zhai, X., Dong, Y., \& Yuan, J. (2018). Investigating learners' technology engagement - A perspective from ubiquitous game-based learning in smart campus. IEEE Access, 6, 10279-10287. https://doi. org/10.1109/ACCESS.2018.2805758

Zhang, A. M. (2003). Transactional distance in web-based college learning environments: Toward measurement and theory construction Doctoral dissertation, Virginia Commonwealth University, Richmond, USA

Publisher's Note Springer Nature remains neutral with regard to jurisdictional claims in published maps and institutional affiliations.

Ghada El-Sayad is an assistant lecturer at College of Management and Technology, Arab Academy for Science, Technology and Maritime Transport (AAST), Business Information Systems (BIS) department. She holds a degree in business administration and a master degree in computer science specialised on information systems from Arab Academy for Science, Technology and Maritime Transport (AAST). She is currently a Ph.D. student in Technology Management, School of Management, Universiti Sains Malaysia. Her areas of interest include Technology Management and online learning. ElSayad Gh. can be contacted at ghadaelsayadaast@gmail.com; ghadaelsayad@aast.edu

Nor Hasliza Md Saad is a lecturer in the Operations Management Section of the School of Management at the Universiti Sains Malaysia (USM). She received her B.A in Computer Information Systems from Temple University, USA and M.Sc in Information Technology in Universiti Sains Malaysia, Malaysia. She received her Doctor of Philosophy in Computer Science from Universiti Teknologi Malaysia, Malaysia. Nor Hasliza Md. Saad can be contacted at norhasliza@usm.my.

Ramayah Thurasamy is currently a Professor of Technology Management at the School of Management, Universiti Sains Malaysia, Visiting Professor King Saud University, Kingdom of Saudi Arabia and Adjunct Professor at Sunway University, Multimedia University and Universiti Tenaga Nasional, Malaysia. His areas of interest include Technology Management and also the use of quantitative methods in management research. His full profile can be accessed from http://www.ramayah.com. T. Ramayah can be contacted at ramayah@usm.my. 